\title{
A EXTENSÃO EM EDUCAÇÃO ESPECIAL E O PROCESSO FORMATIVO DE LICENCIANDOS
}

\author{
Renato Vitor da Silva Tavares \\ Universidade Federal de Alagoas \\ renato.tavares@iefe.ufal.br
}

Neiza de Lourdes Frederico Fumes Universidade Federal de Alagoas neizaf@yahoo.com

\section{Resumo}

O presente estudo apresenta uma reflexão acerca das possibilidades desencadeadas por um projeto de extensão para o processo formativo dos participantes referente à área da Educação Especial e/ou Educação Inclusiva. Para tanto, foi utilizado o grupo focal para a produção dos dados, com estes sendo submetidos à análise de conteúdo. Integraram a pesquisa 15 participantes do projeto (14 graduandos e um graduado em cursos de licenciatura). Em relação aos resultados foram criadas duas categorias: 1) "Nunca tinha discutido e estudado sobre a deficiência. Não se pesquisa, não se fala sobre o assunto"; e 2) "Os conhecimentos construídos no projeto foram muito importantes. São eles que têm transformado a minha docência". A partir das categorias observou-se certa dificuldade dos participantes em identificar ações extensionistas voltadas à Educação Especial e/ou Inclusão, tendo o projeto em questão se caracterizado como relevante, em vista ao enriquecimento e às modificações que suscitou no processo formativo dos participantes.

Palavras-chave: Educação Especial. Formação Docente. Extensão Universitária.

\section{THE EXTENSION IN SPECIAL EDUCATION AND THE UNDERGRADUATES' FORMATIVE PROCESS}

\begin{abstract}
This study presents a reflection on the possibilities triggered by an extension project for the formative process of the participants regarding the area of Special Education and/or Inclusive Education. For this, was used the focus group to produce the data, with these being submitted to content analysis. The research included 15 project participants (14 undergraduate students and one graduate in undergraduate courses). Regarding the results, two categories were created: 1) "I had never discussed and studied disability. There is no research, no talk about the subject"; 2) "The knowledge built on the project was very important. They are the ones who have transformed my teaching". Based on categories were observed difficulties in identifying extension actions aimed at Special Education and/or Inclusion, with the project in question being characterized as relevant, because of the enrichment and the changes it brought about in the formative process of the participants.
\end{abstract}

Keywords: Special Education. Professor Formation. College Extension.

\section{LA EXTENSIÓN EN EDUCACIÓN ESPECIAL Y EL PROCESO DE FORMACIÓN DE ESTUDIANTES UNIVERSITARIOS}

\section{Resumen}

Este estudio presenta una reflexión sobre las posibilidades desencadenadas por un proyecto de extensión para el proceso de formación de los participantes en Educación Especial y/o Educación Inclusiva. Para ello, se utilizó el grupo focal para producir los datos, y estos fueron sometidos a análisis de contenido. La investigación incluyó 15 participantes del proyecto (14 estudiantes y un graduado en cursos de pregrado). En cuanto a los resultados, se crearon dos categorías: 1) "Nunca había discutido y estudiado la discapacidad. No hay investigación, no se habla del tema"; y 2) "El conocimiento construido sobre el proyecto fue muy importante. Ellos son los que han transformado mi enseñanza". A partir de las categorías se observó dificultad en identificar acciones de extensión orientadas a la Educación Especial y/o Inclusión, con el proyecto en cuestión siendo caracterizado como relevante, ante el enriquecimiento y los cambios que generó en el proceso de formación de los participantes.

Palabras clave: Educación Especial. Formación de Profesores. Extensión Universitaria. 


\section{INTRODUÇÃO}

As universidades brasileiras deveriam orientar suas atividades pela indissociabilidade entre ensino, pesquisa e extensão (BRASIL, 1988). No entanto, embora esse preceito seja entendido como tríade, composta por três pilares os quais deveriam balizar o processo formativo, no cotidiano de muitas instituições vê-se equivocadamente o distanciamento, ou até mesmo, a hierarquização dessas três dimensões. Sendo assim, avalia-se como indispensável a retomada desse importante princípio pelas Instituições de Educação Superior, de maneira que a unidade entre as dimensões prevaleça e cada uma delas seja tratada de forma equânime, buscando garantir a qualidade da produção do conhecimento universitário (MOITA; ANDRADE, 2009), da formação profissional e, ainda, do compromisso social com o povo brasileiro.

Nesse sentido, a extensão universitária é compreendida como uma prática acadêmica responsável pela articulação entre as atividades de ensino e de pesquisa, e que deve considerar as demandas da sociedade, sendo, portanto, capaz de produzir conhecimentos significativos para a redução das desigualdades sociais (BRASIL, 2006). Quando comparada às outras dimensões, a extensão é a mais recente, surgindo após a instauração da díade ensino e pesquisa (GONÇALVES, 2015). Desse modo, a extensão enfrenta dificuldades para sua consolidação no âmbito universitário, levando em conta a sua juventude (CASTRO, 2004), assim como seu caráter extramuros e interdisciplinar (PAULA, 2013). Com isso, pode-se afirmar que ainda são necessárias maiores investigações para apreender seu papel no contexto formativo dos discentes e docentes, bem como no desenvolvimento social e na produção do conhecimento.

Neste artigo serão tratadas essas ações no âmbito da Educação Especial e da Educação Inclusiva, as quais não devem ser compreendidas como sinônimos. A Educação Especial pode ser entendida como um campo de conhecimento, de pesquisa e de formação de recursos humanos, além de ser uma modalidade de ensino transversal a todos os níveis, etapas e modalidades de ensino, que busca a remoção de barreiras para a participação plena e efetiva dos alunos (BRASIL, 2008). Por outro lado, a Educação Inclusiva é um movimento mais amplo e se refere a um paradigma educacional pautado nos direitos humanos, em que igualdade e diferença são valores indissociáveis que devem ser considerados para o processo de acesso, permanência e aprendizagem do público-alvo da Educação Especial nos diferentes ambientes educacionais (BRASIL, 2008).

Fundamentado nesse cenário, tem-se percebido que as ações extensionistas em Educação Especial e em Educação Inclusiva apresentam percalços ainda mais elevados para seu fortalecimento, haja vista a realização de atividades de modo esporádico e com pouca 
A extensão em educação especial e o processo formativo de licenciandos

periodicidade (NASCIMENTO, 2008). Entretanto, a extensão voltada a essa temática pode se caracterizar como um componente interessante para o processo formativo dos participantes, considerando-se que nos cursos de formação inicial existe um número reduzido de disciplinas que envolvem os temas inerentes ao público com deficiência, discutindo e ofertando os conteúdos pontualmente e com pouco aprofundamento (FERNANDES et al., 2005; SANTOS; ROCHA; PASSAGLIO, 2016).

À vista disso, configura-se como imprescindível uma sistematização da oferta de ações de extensão, sobretudo, na temática da Educação Especial e da Educação Inclusiva, almejando-se a evolução dos saberes teórico-práticos dos futuros professores para a atuação com a diversidade escolar, superando ou diminuindo os déficits no processo formativo inicial (GOÉS; FERREIRA, 2013). Nessa perspectiva, ações, como o projeto de extensão do presente relato, podem se qualificar como essenciais para a modificação da realidade local na área da Educação Especial.

Com base no exposto, este estudo tem o objetivo de apresentar uma reflexão acerca das possibilidades desencadeadas por um projeto de extensão para o processo formativo dos participantes no que se refere à área da Educação Especial e/ou Inclusão.

\section{PROCEDIMENTOS METODOLÓGICOS}

\section{Caracterização do Estudo}

O presente estudo adotou uma abordagem qualitativa, que para Minayo (2001) é caracterizada pela sua busca da compreensão de um aspecto social e pela atuação junto ao universo de significados, correspondendo assim um espaço profundo de relações, de modo que os processos e os fenômenos não podem ser minimizados à operacionalização de variáveis. Somado a isso, Silveira e Córdova (2009) apontam que a pesquisa qualitativa contempla aspectos que não necessitam ser quantificados, os quais possibilitam compreender e explicar as conexões entre o mundo objetivo e a subjetividade do indivíduo.

Além disso, foi adotado o tipo descritivo para a pesquisa, que tem como objetivo descrever as características de determinada população ou fenômeno, podendo ou não estabelecer relações entre as variáveis, sem que ocorra a manipulação dos fatos pelo pesquisador (PRODANOV; FREITAS, 2013).

\section{Caracterização do Projeto e do Grupo Estudado}

O projeto de extensão em Educação Especial/Educação Inclusiva, em sua $3^{a}$ edição, foi realizado em parceria com a pró-reitoria de extensão de uma universidade pública da Região 
A extensão em educação especial e o processo formativo de licenciandos

Nordeste, com seu desenvolvimento sendo vinculado às ações de extensão de fluxo contínuo da instituição. Ocorreu em 10 encontros mensais que perduraram por um ano letivo e que eram realizados, preferencialmente, na primeira sexta-feira de cada mês, totalizando 30 horas de carga horária extensionista.

No projeto foram abordadas diferentes temáticas da área da Educação Especial e da inclusão de Estudantes com Deficiência, Transtornos Globais do Desenvolvimento e Altas Habilidades/Superdotação no ambiente escolar. Os temas englobaram a caracterização da identidade profissional docente, o lugar da teoria e do Atendimento Educacional Especializado na prática pedagógica inclusiva, as estratégias pedagógicas para o ensino de estudantes com deficiência intelectual, surdez/surdo-cegueira, autismo, deficiência física, deficiência visual e altas habilidades/superdotação. Por fim, focou-se no processo de avaliação da aprendizagem na perspectiva da Educação Inclusiva.

O projeto tinha como objetivo ampliar o conhecimento relativo ao trabalho pedagógico com esse público em contexto educativo inclusivo, focando, principalmente, na elaboração de propostas e recursos pedagógicos inclusivos, considerando as especificidades do público-alvo da Educação Especial na Educação Básica.

Os proponentes do projeto eram estudantes de graduação e de pós-graduação stricto sensu, professores universitários de uma instituição pública federal de um estado nordestino e professores da Educação Básica de uma rede pública municipal de educação. Todos os proponentes eram integrantes de um grupo de estudos e pesquisas interessado na temática da Educação Especial.

O projeto foi divulgado por meio de redes sociais e de contatos com representantes das secretarias de educação de diferentes municípios. A adesão ao projeto era gratuita e os participantes poderiam comparecer apenas aos encontros que julgassem mais interessantes, ainda que a certificação ocorresse somente para aqueles que frequentassem $75 \%$ dos encontros, conforme as normas institucionais. Ao final dos 10 encontros mensais referentes às palestras/discussões sobre as temáticas do projeto de extensão foi proposto um momento de escuta dos participantes, para que estes pudessem refletir sobre o projeto e seus aprendizados. Esse momento ocorreu em três cidades (a capital do estado, uma cidade do Agreste e uma cidade da Zona da Mata), as quais tiveram maior número de participantes na ação de extensão.

Para essa pesquisa foram eleitos 15 participantes, sendo 13 do gênero feminino e dois do gênero masculino, provenientes de uma cidade do Agreste. Destaca-se, ainda, que 13 deles eram graduandos de um curso de Pedagogia e um de Ciências Biológicas de uma universidade pública 
A extensão em educação especial e o processo formativo de licenciandos

estadual. Exclusivamente um dos participantes já havia finalizado a graduação em Pedagogia e era cursista de uma Pós-Graduação lato sensu em Educação Especial e Educação Inclusiva.

Vale destacar que os participantes desse grupo focal foram escolhidos para integrar o grupo estudado por se caracterizarem como o maior quantitativo dentre os três momentos de reflexões acerca do projeto e também pelo fato de sua maior parte ser composta por pessoas em processo de formação inicial.

Desse grupo, quatro participantes já estavam inseridos no mercado de trabalho e atuando na área educacional, sendo três como professores (dois deles na área de Educação Infantil) e um como secretário escolar.

Os participantes do estudo foram nomeados com a letra $\mathrm{P}$, que faz referência à palavra participante, seguida de um número entre um e 15, sendo este determinado pela ordem de fala/apresentação no momento de início do grupo focal. Esse ponto buscou garantir o anonimato dos indivíduos, respeitando os princípios éticos em pesquisas com seres humanos.

Ainda quanto aos aspectos éticos, a pesquisa em questão foi aprovada pelo Comitê de Ética em Pesquisa da Universidade Federal de São Carlos (UFSCar), com o parecer de número: $382 / 2011$.

\section{Instrumento de Produção de Dados}

Para a produção de dados foi utilizado o grupo focal. De acordo com Backes et al. (2011), consiste em uma técnica que promove uma grande problematização sobre determinado tema ou foco específico a partir da interação grupal. Além do mais, para os mesmos autores, esta técnica é desenvolvida em uma perspectiva dialética, levando em consideração que o grupo possui objetivos comuns e os participantes procuram abordar o tema/foco como uma equipe.

Para Debus (1997) e Pizzol (2004), o grupo focal deve envolver entre seis e 15 pessoas, as quais devem ser dispostas de forma a propiciar o diálogo efetivo entre si e a discussão adequada acerca da temática. Do mesmo modo, são necessários equipamentos para gravação de áudio ou vídeo, possibilitando retomar o acesso aos conteúdos captados (TRAD, 2009). Assim, permite-se uma maior precisão na análise por meio da identificação de pontos que podem não ter sido percebidos anteriormente.

Especificamente no projeto em questão, o grupo focal teve duração aproximada de $1 \mathrm{~h} 30$ e foi organizado em uma sala de uma universidade local com os participantes distribuídos em uma mesa, de maneira que a câmera pudesse visualizar e registrar todos eles no momento das discussões. Os pesquisadores que conduziram as filmagens posicionaram-se em frente à mesa em que os participantes estavam alocados. Primeiramente, os responsáveis realizaram a leitura e a 
A extensão em educação especial e o processo formativo de licenciandos

apresentação do Termo de Consentimento Livre e Esclarecido, que foi posteriormente assinado pelos participantes. Ressalta-se ainda que nessa etapa foi explicado o funcionamento do grupo focal e os procedimentos de registro e de armazenamento dos dados.

Em seguida, os pesquisadores expuseram que o objetivo do grupo focal era a realização de uma avaliação acerca da metodologia proposta para o funcionamento do projeto de extensão, utilizando-se, para isso, de algumas questões norteadoras com o intuito de desencadear a discussão entre os participantes. Essas questões buscaram compreender: 1) as motivações para a participação no projeto, de modo a verificar as expectativas iniciais acerca da atividade extensionista e se essas foram atendidas, como ainda o que levou à participação no projeto e a existência de cursos/projetos de extensão na temática da Educação Especial e da Educação Inclusiva na localidade de origem; 2) análise da organização do projeto, por meio da verificação da pertinência das temáticas, da excedência ou da ausência de algum tópico de discussão, do conhecimento ou não sobre o referencial teórico abordado, do tempo de duração dos encontros, do intervalo de duração entre um encontro e outro, dos locais de realização do projeto e das metodologias propostas; e 3) os desencadeamentos do projeto, em que se buscou perceber a compreensão dos participantes sobre a relação teoria e prática na constituição da práxis pedagógica inclusiva, e se houve algum impacto do projeto no processo formativo inicial e na vida profissional dos participantes.

\section{Procedimentos de Análise dos Dados}

Para a análise dos dados, o conteúdo das filmagens do grupo focal foi transcrito integralmente e submetido aos procedimentos da análise de conteúdo de Bardin (2011). Minayo (2014) evidencia que a análise de conteúdo é o procedimento mais utilizado para o tratamento de dados advindos da pesquisa qualitativa e, enfatiza ainda que, por meio dessa análise, as inferências sobre dados de determinado contexto podem ter caráter válido e replicável.

A análise de conteúdo, segundo Bardin (2011), é entendida como um conjunto de técnicas de análise que visa obter, por meio de procedimentos sistemáticos e objetivos, a descrição do conteúdo das mensagens, permitindo, assim, a interpretação e inferência dos conhecimentos correlatos às condições de produção e recepção dessas mensagens. Para Cavalcante, Calixto e Pinheiro (2014, p. 14), a análise de conteúdo oferece a oportunidade para "a descrição das mensagens e das atitudes atreladas ao contexto da enunciação, bem como as inferências sobre os dados coletados".

A partir do uso da análise de conteúdo foram definidas duas categorias para o tratamento dos dados: a primeira denominada "Nunca tinha discutido e estudado sobre a deficiência. Não se 
A extensão em educação especial e o processo formativo de licenciandos

pesquisa, não se fala sobre o assunto"; e a segunda intitulada "Os conhecimentos construídos no projeto foram muito importantes. São eles que têm transformado a minha docência".

\section{RESULTADOS E ANÁLISES}

\section{Nunca tinha discutido e estudado sobre a deficiência. Não se pesquisa, não se fala sobre o assunto}

No que se remete à primeira categoria, trata-se sobre a incipiência do tema nos cursos de formação de professores e de ações relacionadas à educação e à inclusão do público-alvo da Educação Especial na esfera universitária. Inicialmente, por meio das falas dos participantes, percebeu-se que o estudo da temática estava circunscrito a uma única disciplina, ainda que também fosse destacada a sua insuficiência para dar conta de enfoques distintos referentes à deficiência e ao processo educativo dessas pessoas. As falas a seguir explicitam o exposto anterior:

A disciplina foi importante, mas ficou vaga (P9);

Ficavam muitas dúvidas [na disciplina] (P11);

[Na disciplina] a gente se limita a alguns detalhes, porque o tempo é pequeno (P5);

A gente só teve essa disciplina [...] fica ali só naquela parte, passou a disciplina e não quer mais saber (P4);

A gente não tem como ver na matéria de Educação Inclusiva de forma ampla (P3).

Esse resultado não difere de outros trabalhos que apontam para a indispensabilidade de os cursos de graduação, nomeadamente os de formação de professores, incluírem disciplinas e conteúdos relativos à educação de pessoas com deficiência em contextos inclusivos, tendo em vista a necessidade de formação de um profissional/professor qualificado para atuar com a diversidade em seus ambientes educativos (MOREIRA, 2004). No entanto, para Martins (2012), muitas das Instituições de Educação Superior (IES) não estruturam seus projetos pedagógicos de curso de maneira apropriada para ofertar componentes curriculares específicos a essa temática e, quando ofertados, apresentam carga horária reduzida ou são disciplinas eletivas, o que não contribui efetivamente para a formação das novas gerações.

Conforme Brancatti (2008), uma disciplina intrínseca à temática da inclusão tem caráter fundamental em despertar o interesse dos alunos, informá-los e auxiliá-los na construção do 


\section{A extensão em educação especial e o processo formativo de licenciandos}

conhecimento. Todavia, é de responsabilidade do curso e dos demais componentes curriculares abordar em seus conteúdos a realidade das pessoas com deficiência.

Santos (2016) corrobora com o explicitado por Brancatti (2008) quando afirma que se faz necessária uma reformulação do currículo dos cursos de graduação, de modo que sejam infundidos os princípios e os conhecimentos da Educação Inclusiva por todas as disciplinas do curso. Para isso, todos os professores da Educação Superior, em conjunto com os demais atores das IES, precisam ser provocados a garantir a transversalidade do paradigma da inclusão educacional, pensando em um desenho universal da aprendizagem que venha a atender a diversidade da população universitária. Essas mudanças têm o objetivo de fomentar a prática pedagógica inclusiva e fortalecer o processo formativo de seus alunos no que se alude ao públicoalvo da Educação Especial, de forma que esses sejam formados a atuar com as pessoas com deficiência em sua prática profissional.

Além das mudanças nas matrizes curriculares dos cursos das IES, configura-se como primordial a ampliação de oportunidades de aprendizagem constantes acerca da temática, a fim de que se possa ter acesso aos saberes constitutivos desse campo de conhecimento e dessa área de atuação profissional. Entretanto, os participantes dessa pesquisa relataram dificuldades na busca de ações e de estudos destinados à Educação Inclusiva e/ou Especial:

$\mathrm{Na}$ nossa universidade, aqui mesmo não tem projeto assim, projeto de extensão desse nível (P8);

A gente não encontra cursos de extensão por perto (P10);

Oferecem algumas palestras [...] só que uma vez no ano que ocorre. Fica por isso (P3);

[Os cursos ofertados] ficam muito restritos a apenas uma temática [autismo] (P3);

Tem a ver também a falta de grupo de estudos, porque não se faz um grupo de estudos, não se pensa nisso (P1).

Com base nos excertos, identifica-se que as ações disponibilizadas acontecem esporadicamente e, quando acontecem, são destinadas a um mesmo tema, não existindo outras ações formativas de maneira sistemática.

De acordo com Lustosa (2018), um dos fatores para a carência de estudos na temática da Educação Especial e Inclusiva no estado de execução do projeto de extensão se deve à juventude dos programas de pós-graduação na Região Nordeste e, consequentemente, ao fato de as produções sobre esses conteúdos iniciarem tardiamente em comparação às Regiões Sul e Sudeste. Além disso, para a mesma autora, a ausência de pesquisas específicas na área da Educação Especial pode ser caracterizada pelo número limitado de pesquisadores e pela individualidade em 
A extensão em educação especial e o processo formativo de licenciandos

que estes atuam, considerando-se que na maior parte dos programas de pós-graduação em Educação da Região Nordeste não há a possibilidade da criação de linhas de pesquisas relacionadas à Educação Especial.

$\mathrm{Na}$ universidade pública em que o projeto foi desenvolvido, estritamente no programa de pós-graduação em Educação, ocorreu a criação de uma linha de pesquisa referente à educação e inclusão da pessoa com deficiência no ano de 2016, confluindo com o exposto por Lustosa (2018). Deve-se evidenciar que nessa universidade as produções direcionadas à inclusão tiveram início somente a partir do ano de 2010 (LUSTOSA, 2018), ou seja, é uma produção extremamente recente e pouco expressiva quantitativamente em relação aos outros estados brasileiros. Contudo, espera-se que com a criação desta linha de pesquisa avanços significativos sejam suscitados na produção acadêmica e na formação de profissionais para atuar com as pessoas com deficiência, Transtornos Globais do Desenvolvimento e altas habilidades/superdotação.

De modo complementar, deve-se ressaltar que, nesse estado, a maior parte da produção do conhecimento e publicações é realizada por apenas um grupo de estudos (PAVEZI; MAINARDES, 2016).

Essa conjuntura colabora na compreensão dos resultados obtidos, ao mesmo tempo em que demonstra que as produções sobre a Educação Especial e a Educação Inclusiva são ainda reduzidas no local de materialização do projeto de extensão, tendo a imprescindibilidade de criação de mais grupos e ambientes de discussão sobre esse tema, para que, assim, os conhecimentos possam ser difundidos com maior amplitude na sociedade.

\section{Os conhecimentos construídos no projeto foram muito importantes. São eles que têm} transformado a minha docência

No que diz respeito à segunda categoria, são abordados os conhecimentos oriundos da extensão universitária em Educação Especial e Educação Inclusiva no processo formativo de professores, tal como a relação teoria e prática na (trans)formação da prática pedagógica inclusiva dos sujeitos.

Os excertos a seguir mostram que os participantes entendem a extensão universitária, especificamente, o projeto de extensão, como um complemento dos estudos desenvolvidos em uma disciplina sobre a temática da inclusão que a maioria dos participantes teve na formação inicial:

Tivemos tanto a disciplina que foi muito bem ofertada quanto também esse projeto que aprimorou mais a nossa formação (P1); 
Eu achei muito rico na questão de complementar a matéria e dar aquele aparato a mais [na formação] (P3);

O projeto veio a completar a disciplina (P8);

Foi complemento da disciplina, até porque a gente percebe assim que o projeto foi para complementar as nossas experiências (P6);

Com as experiências desses professores e a teoria que nós adquirimos foi que fez com que a gente tivesse esse aparato sobre a educação inclusiva maior do que simplesmente uma disciplina cursada (P1);

Ficavam muitas dúvidas [na disciplina], e com a temática usada lá [no projeto] ia esclarecendo muita coisa sobre a deficiência (P11).

Para Dagnino (2015), a extensão é representada na universidade com esta finalidade, apresentada nos fragmentos acima - uma complementação das atividades de ensino e pesquisa, com o objetivo de identificar os problemas existentes na sociedade e agir para resolvê-los, de forma que o conhecimento gerado possa ser aproveitado e utilizado posteriormente.

Apesar de suas múltiplas alternativas para o fortalecimento do processo formativo, a extensão ainda é vista de maneira marginalizada, assim como aponta Maciel (2011). Isto posto, valoriza-se, primeiramente, a produção científica, depois as atividades relacionadas ao ensino e, por último, as atividades extensionistas, com grande parcela dos docentes e discentes desconhecendo o impacto social desencadeado pela extensão (MACIEL, 2011).

No entanto, dando importância ao citado anteriormente, o Plano Nacional de Educação 2014/2024, em uma de suas metas, determina que deverá ocorrer a curricularização da extensão, de modo que esta seja incorporada no projeto pedagógico dos cursos de graduação como componente curricular, estando articulada às demais atividades acadêmicas e com, no mínimo, 10\% dos créditos curriculares da graduação (BRASIL, 2014).

A partir disso, com a curricularização da extensão, acredita-se, inicialmente, em uma maior possibilidade de os alunos vivenciarem as ações extensionistas, indo além da carga horária flexível estipulada pelos cursos de graduação. Ademais, entende-se que por meio da curricularização, a extensão desencadeará um papel de maior efetividade na formação do discente, a qual poderá ser (res)significada, tendo em vista que o discente estará em contato com uma ou mais demandas sociais que necessitarão da aplicação dos saberes teóricos apreendidos para solucioná-las, gerando, assim, conhecimentos produzidos na atuação extensionista, os quais deverão ser difundidos para a sociedade (MACIEL, 2011). Por conseguinte, as práticas curriculares de extensão podem contribuir para a transformação do aluno, do professor e da sociedade (RESENDE et al., 2017). 


\section{A extensão em educação especial e o processo formativo de licenciandos}

No que tange à formação de professores para atuar na perspectiva da Educação Inclusiva, Carneiro (2015) indica que esta é precária porque os cursos de graduação não oferecem uma formação adequada e pautada nos aspectos da diversidade. Sendo assim, a extensão universitária a respeito da temática da inclusão se configura como de caráter relevante para diminuir e/ou suprir as falhas decorrentes do processo formativo inicial e proporcionar aos participantes um ambiente de diálogo e possibilidade de construção de novos saberes, necessários para a atuação profissional. Essa relevância da extensão em Educação Inclusiva, especificamente do projeto de extensão, é relatada nos recortes a seguir:

A gente ter uma temática desenvolvendo essa questão da Educação Inclusiva, já é um leque de informações muito importante para nossa formação (P3);

Tinham até coisas que eu mesma não sabia e vim aprender com o projeto de extensão (P4);

Quando você tem uma janela que abre aquele assunto você vai buscar mais, o projeto de extensão nos proporcionou isso (P5);

A minha formação seria carente sem esse projeto que a gente teve em relação à Educação Inclusiva (P10);

O projeto foi uma coisa muito positiva, tanto na minha vida acadêmica quanto na minha vida profissional (P2).

Desta forma, percebe-se que o projeto de extensão propiciou ganhos significativos na formação dos sujeitos, pelo fato de discutir e aprofundar temáticas atuais na área da Educação Inclusiva e Especial, mais particularmente tratando de aspectos relacionados à inclusão escolar de estudantes do público-alvo da Educação Especial. Identificou-se pelas falas dos participantes do projeto de extensão o exposto por Noronha (2017), de que a participação no projeto não se deu apenas pela certificação obtida, mas, sim, pela conscientização dos participantes em reconhecer as falhas na formação e ir em busca de superação dessas lacunas, de modo a adquirir habilidades que embasem a sua prática profissional futura no contexto em questão.

Outro ponto relevante relatado pelos sujeitos foi a reflexão no tocante à formação docente e à prática pedagógica, assim como à aplicação do conhecimento construído no projeto nos contextos universitário e profissional:

Possibilitou uma reflexão muito grande para gente, para adentrar no processo educativo (P3);

Reflete até nos trabalhos que a gente faz no curso de formação, que a gente não tinha antes [...] e está tendo agora com essa clara visão da Educação Inclusiva (P1); 


\section{A extensão em educação especial e o processo formativo de licenciandos}

Saber trabalhar, saber ser mais humano, saber identificar, sentir essas dificuldades que o outro sente, se colocar no lugar dele aprimora a nossa prática e o projeto possibilitou isso para a gente em vários momentos (P3);

Eu pude também chegar onde eu trabalho e incentivar os meus colegas a refletir sobre sua prática em sala de aula, que muitas vezes não acontece a inclusão (P2).

Noronha (2017) relata que a extensão não objetiva apenas a formação do futuro professor, mas, também, oportuniza que esse perceba sua realidade e possa refletir sobre a importância desse processo de aprendizagem no aprimoramento de sua prática pedagógica, no suporte metodológico alcançado e, ainda, nas transformações no contexto escolar e na sociedade, a partir da aplicação do conhecimento obtido. Sendo assim, o conhecimento deve ser difundido com os pares, tendo por objetivo a mudança da realidade de cada ambiente, buscando o desenvolvimento de ações e práticas destinadas não somente aos alunos com deficiência, mas para todos.

Ainda na segunda categoria, referindo-se à relação teoria e prática na (trans)formação da prática pedagógica inclusiva dos sujeitos, foi identificada uma ênfase no saber prático em decorrência de vivências de/com pares mais experientes no modo de agir com os estudantes com deficiência, como pode ser visto a seguir:

Possibilitou que a gente pudesse ver relatos de professores, como eles lidavam com as crianças em sala de aula. Coisa que a gente só vê na teoria, que não vê aplicado na prática (P2);

Os eventos que estão tendo [...] levam muito as teorias, [...] mas a prática dá um norte. Faz com que a gente saia de lá com um conhecimento. Não só com a informação (P6);

As experiências dos professores que eles passaram pra gente foi muito bom (P11);

A gente teve experiências de professores e isso é rico (P3).

Para Alves (2012), assim como os participantes deste estudo, a produção de um saber prático educativo surge por meio da reflexão da experiência pessoal partilhada entre os pares, que pode instrumentalizar a ação do docente perante os casos vivenciados em sala de aula por professores mais experientes no tema.

Apesar disso, não se deve desvalorizar o papel da teoria no contexto educativo, tendo em conta que a articulação entre teoria e prática conduz à práxis, de modo que a atividade teórica sozinha não transforma a realidade, mas a reflexão (teoria) e a ação (prática) podem transformar e proporcionar uma prática pedagógica inclusiva de qualidade para os alunos (SOUSA, 2017). 
O participante seis (P6) aponta exatamente o exposto anteriormente por Sousa (2017), em que a prática pedagógica inclusiva "precisa ser pensada, precisa ser, obviamente, feita e depois precisa ser analisada".

Por fim, os participantes deste estudo discutiram acerca do que é a prática pedagógica inclusiva e como ela se caracteriza, cujas considerações são apresentadas em seguida:

[a prática pedagógica inclusiva] é prática inconstante e dinâmica, que nunca é uma coisa estática [...], ela está sempre se refazendo (P6);

O contato com a prática pedagógica inclusiva [...] mudou a perspectiva de ter o aluno [com deficiência] em sala de aula (P8);

A Educação Inclusiva é um tema muito amplo, não tem como você querer aprender tudo em uma tarde ou tudo ao longo desses dez encontros (P6);

É desde o planejamento, as observações que a gente faz e também como avaliar o aluno, tudo isso tem que ser pensado e depois de todo esse aparato de conhecimento a gente está com isso mais claramente (P1).

Desses resultados, dois pontos extremamente relevantes sobre a prática pedagógica inclusiva merecem destaque: 1) seu caráter flexível, em que é necessário orientar-se pela máxima ação-reflexão-ação para que se possa identificar as falhas, os acertos e as possibilidades, de forma a estar sempre comprometido em proporcionar uma educação condizente com a realidade das pessoas com deficiência; e 2) a necessidade de investir de maneira consistente na formação de professores (inicial e continuada) para atuar em uma perspectiva inclusiva. Uma disciplina ou ações de extensão, apesar de serem imprescindíveis, não são suficientes para a formação dos professores para atuar com o público-alvo da Educação Especial, necessitando de uma continuidade dos estudos referentes à Educação Inclusiva para além da formação inicial, durando por todo o exercício da docência (SANTOS, 2016).

\section{CONSIDERAÇÕES FINAIS}

Esta pesquisa buscou apresentar uma reflexão e discutir acerca da atividade de extensão em Educação Especial e Inclusão no processo formativo de universitários participantes de um projeto de extensão.

Inicialmente, os participantes do referido projeto expuseram uma grande dificuldade em identificar ações extensionistas e estudos que fossem produzidos e destinados à área da Educação Especial e Inclusiva, tendo contato com esta temática apenas em uma disciplina da graduação, a qual, apesar de ser insuficiente para suprir as inquietudes dos alunos, teve caráter muito importante para despertar o interesse em relação a esses temas. 
A extensão em educação especial e o processo formativo de licenciandos

Sendo assim, acredita-se ser necessária uma reformulação dos currículos de graduação, de maneira a, além de perpassar os conteúdos inerentes ao público alvo da Educação Especial por todo o curso e em cada disciplina, propor ações de extensão de modo sistemático e que proporcionem ganhos na formação educacional dos discentes. Desse modo, a curricularização da extensão pode vir a ser um aspecto relevante no fortalecimento do processo formativo, considerando que a partir das modificações curriculares ocorrerá uma maior periodicidade no desenvolvimento das ações de extensão e a consolidação e/ou fortalecimento da indissociabilidade entre as atividades de ensino, pesquisa e extensão, tornando os conhecimentos produzidos mais significativos para os proponentes, participantes e sociedade.

Por meio da curricularização da extensão, as ações destinadas à Educação Especial e Educação Inclusiva poderão ganhar maiores espaços de discussão nos cursos de formação inicial, levando em conta a grande incipiência atual e a possibilidade de suprir as falhas relacionadas a esses conteúdos na graduação. Para isso, faz-se necessário que os docentes da Educação Superior estejam em processo constante de formação e de reflexão da sua prática pedagógica, para que possam ter sensibilidade em perceber as lacunas existentes na formação inicial de seus alunos, sendo uma delas o paradigma da inclusão educacional, propondo ações, tais como projetos e programas que visem à modificação da realidade local.

Em vista disso, a partir do contato com a extensão universitária em Educação Especial e Inclusão por meio do projeto de extensão, foi possível verificar alterações e ganhos significativos em relação ao processo formativo dos alunos e da ação dos docentes, considerando-se o reconhecimento das lacunas na formação e a busca por novas experiências formativas por parte dos discentes. Além disso, outro fator que indica a evolução dos saberes inerentes à temática da Educação Especial é a aplicação dos conhecimentos construídos no projeto de extensão na vida cotidiana dos participantes, seja no âmbito universitário ou profissional.

Portanto, as atividades extensionistas voltadas à Educação Especial e Inclusiva caracterizam-se como um ponto extremamente relevante para o enriquecimento do processo formativo dos discentes da Educação Superior, embora seja necessária a estruturação de ações, assim como uma continuidade dos estudos referentes à temática que venha a durar por toda a vida profissional, a partir do compromisso das instituições empregadoras e dos sistemas educacionais.

\section{REFERÊNCIAS}

ALVES, Ivelise Kraide. A Formação do Docente no Contexto da Educação Inclusiva. Monografia (Especialização em Educação Especial e Processos Inclusivos) - Programa de Pós-Graduação em 
A extensão em educação especial e o processo formativo de licenciandos

Educação, Universidade Federal do Rio Grande do Sul, Porto Alegre, 2012. Disponível em: https://www.lume.ufrgs.br/bitstream/handle/10183/69898/000874685.pdf. Acesso em: 26 dez. 2019.

BACKES, Dirce Stein. et al. Grupo focal como técnica de coleta e análise de dados em pesquisas qualitativas. O Mundo da Saúde. São Paulo, v. 35, n. 4, 2011. Disponível em:

http://bvsms.saude.gov.br/bvs/artigos/grupo_focal_como_tecnica_coleta_analise_dados_pesquisa_q ualitativa.pdf. Acesso em: 26 dez. 2019.

BARDIN, Laurence. Análise de Conteúdo. 6. ed. Lisboa: Edições 70, 2011.

BRANCATTI, Paulo Roberto. O papel da disciplina educação física para pessoas com necessidades especiais no curso de licenciatura em Educação Física da FCT/UNESP de Presidente Prudente. In: III CONGRESSO BRASILEIRO DE EDUCAÇÃO ESPECIAL, 2008, São Carlos. Anais do III Congresso Brasileiro de Educação Especial. São Carlos: Universidade Federal de São Carlos, 2008.

BRASIL. Senado Federal. Constituição da República Federativa do Brasil - 1988. Brasília, DF: Centro Gráfico, 1988.

BRASIL. Ministério da Educação. Secretaria de Ensino Superior. Fórum de Pró-Reitores de Extensão nas Universidades Públicas Brasileiras. Indissociabilidade entre ensino-pesquisaextensão e a flexibilização curricular: uma visão da extensão. Porto Alegre: UFRGS; Brasília: MEC/Sesu, 2006.

BRASIL. Ministério da Educação. Secretaria de Educação Especial (SEESP). Política Nacional de Educação Especial na Perspectiva da Educação Inclusiva. Brasília, DF: MEC/SEESP, 2008.

BRASIL. Lei no 13.005, de 25 de junho de 2014. Aprova o Plano Nacional de Educação - PNE 2014-2024 e dá outras providências. Brasília, Câmara dos Deputados: Edições Câmara, 2014.

CARNEIRO, Moaci Alves. LDB fácil: leitura crítico-compreensiva artigo por artigo. Petrópolis: Vozes, 2015.

CASTRO, Luciana Maria Cerqueira. A universidade, a extensão universitária e a produção de conhecimentos emancipadores. In: REUNIÃO ANUAL DA ANPED, 27, 2004, Caxambu. Anais... Caxambu: ANPEd, 2004.

CAVALCANTE, Ricardo Bezerra; CALIXTO, Pedro; PINHEIRO, Marta Macedo Kerr. Análise de conteúdo: considerações gerais, relações com a pergunta de pesquisa, possibilidades e limitações do método. Revista Informação \& Sociedade: Estudos. João Pessoa, v. 24, n. 1, jan./abr. 2014. Disponível em:

http://www.periodicos.ufpb.br/ojs/index.php/ies/article/view/10000/10871. Acesso em: 23 dez. 2019.

DAGNINO, Renato. Como é a universidade de que o Brasil precisa? Revista Avaliação. Campinas, Sorocaba, v. 20, n. 2, jul. 2015. Disponível em: http://www.scielo.br/pdf/aval/v20n2/1414-4077-aval-20-02-00293.pdf. Acesso em: 22 dez. 2019. 
A extensão em educação especial e o processo formativo de licenciandos

DEBUS, Mary. Manual para excelencia en la investigación mediante grupos focales. Washington D.C. Academy for Educational Development, 1997.

FERNANDES, Edicléa Mascarenhas. et. al. A inclusão de pessoas com necessidades especiais através dos projetos de extensão do Núcleo de Estudos e Pesquisas em Educação Inclusiva da UERJ. Interagir: Pensando a Extensão, Rio de Janeiro, n. 7, jan./jul. 2005. Disponível em: https://www.e-publicacoes.uerj.br/index.php/interagir/article/view/21396/15514. Acesso em: 19 nov. 2019.

GÓES, Maria Cecília Rafael de; FERREIRA, Júlio Romero. Sobre inclusão, políticas públicas e práticas pedagógicas. In: GÓES, Maria Cecília Rafael de; LAPLANE, Adriana Lia Friszman de. Políticas e práticas de educação inclusiva. 4. ed. Campinas: Autores Associados, 2013, p. 21 44.

GONÇALVES, Nadia Gaiofatto. Indissociabilidade entre Ensino, Pesquisa e Extensão: um princípio necessário. Perspectiva. Florianópolis, v. 33, n. 3, set/dez. 2015. Disponível em: https://periodicos.ufsc.br/index.php/perspectiva/article/viewFile/37162/pdfa. Acesso em: 26 dez. 2019.

LUSTOSA, Ana Valéria Marques Fortes. Teses e dissertações em Educação Especial na região nordeste no período de 1997 a 2012. Revista Educação Especial. Santa Maria, v. 31, n. 60, jan./mar. 2018. Disponível em:

https://periodicos.ufsm.br/educacaoespecial/article/view/18997/pdf. Acesso em: 30 nov. 2019.

MACIEL, Lucas Ramalho. Política Nacional de Extensão: Perspectivas para a Universidade Brasileira. Participação. Brasília, v. 10, n. 18, dez. 2011. Disponível em: http://periodicos.unb.br/index.php/participacao/article/view/22735. Acesso em: 16 ago. 2019.

MARTINS, Lúcia de Araújo Ramos. Reflexões sobre a formação de professores com vistas à educação inclusiva. In: MIRANDA, Theresinha Guimarães; GALVÃO FILHO, Teófilo Alves (Orgs.). O professor e a educação inclusiva: formação, práticas e lugares. Salvador: EDUFBA, 2012. p. 25-38.

MINAYO, Maria Cecília de Souza. (Org.) Pesquisa social: teoria, método e criatividade. Petrópolis: Vozes, 2001.

MINAYO, Maria Cecília de Souza. O desafio do conhecimento: pesquisa qualitativa em saúde. 14. ed. São Paulo: Hucitec, 2014.

MOITA, Filomena Maria Gonçalves da Silva Cordeiro; ANDRADE, Fernando Cézar Bezerra de. Ensino-pesquisa-extensão: um exercício de indissociabilidade na pós-graduação. Revista Brasileira de Educação. Rio de Janeiro, v. 14, n. 41, maio/ago. 2009. Disponível em: http://www.scielo.br/pdf/rbedu/v14n41/v14n41a06.pdf. Acesso em: 23 dez. 2019.

MOREIRA, Laura Ceretta. Universidade e alunos com necessidades educacionais especiais: das ações institucionais às práticas pedagógicas. Tese (Doutorado em Educação), Faculdade de Educação, Universidade de São Paulo, São Paulo, 2004.

NASCIMENTO, Simone do Socorro Freitas do. Representações sociais de professores sobre formação continuada em Educação Especial. Dissertação (Mestrado em Educação) Programa de Pós-Graduação em Educação, Universidade Estácio de Sá, Rio de Janeiro, 2008. 
A extensão em educação especial e o processo formativo de licenciandos

Disponível em:

http://estacio.br/mestrado/educacao/dissertacoes/Dissert_RSPE_simone_do_socorro.pdf.

Acesso em 26 dez. 2019.

NORONHA, Lilian Freire. Formação continuada de professores do ensino médio para a educação especial na perspectiva da educação inclusiva. Mestrado Profissional em Ensino Tecnológico - Instituto Federal de Educação, Ciência e Tecnologia do Amazonas, Campus Manaus Centro, 2017. Disponível em: http://repositorio.ifam.edu.br/jspui/handle/4321/77. Acesso em: 23 dez. 2019.

PAULA, João Antônio de. A extensão universitária: história, conceito e propostas. Interfaces Revista de Extensão. Belo Horizonte, v. 1, n. 1, jul./nov. 2013. Disponível em: https://www.ufmg.br/proex/revistainterfaces/index.php/IREXT/article/view/5/pdf. Acesso em: 21 dez. 2019.

PAVEZI, Marilza; MAINARDES, Jefferson. A pesquisa sobre a política de Educação Especial no Estado de Alagoas (2003-2015): um levantamento preliminar. In: V CONGRESSO IBEROAMERICANO DE POLÍTICA E ADMINISTRAÇÃO DA EDUCAÇÃO/VIII CONGRESSO LUSO-BRASILEIRO DE POLÍTICA E ADMINISTRAÇÃO DA EDUCAÇÃO, 2016, Goiânia. Anais do V Congresso Ibero-Americano de Política e Administração da Educação/VII Congresso Luso Brasileiro de Política e Administração da Educação. Disponível em: http://www.anpae.org.br/iberoamericano2016/publicacao/cntnt/artigos/eixo_1/E1_A073.html . Acesso em: 22 dez. 2019.

PIZZOL, Silvia Janine Servidor de. Combinação de grupos focais e análise discriminante: um método para tipificação de sistemas de produção agropecuária. Revista de Economia e Sociologia Rural. Brasília, v. 42, n. 3, jul./set. 2004. Disponível em: http://www.scielo.br/pdf/resr/v42n3/24505.pdf. Acesso em: 21 dez. 2019.

PRODANOV, Cleber Cristiano; FREITAS, Ernani Cesar de. Metodologia do trabalho científico: métodos e técnicas de pesquisa e do trabalho acadêmico. 2. ed. Novo Hamburgo: Feevale, 2013.

RESENDE, Márcia Colamarco Ferreira. et al. A curricularização das práticas de extensão na PUC Minas. Conecte-se! Revista Interdisciplinar de Extensão. Belo Horizonte, v. 1, n. 2, 2017. Disponível em: http://periodicos.pucminas.br/index.php/conecte-se/article/view/16748. Acesso em: 21 dez. 2019.

SANTOS, Soraya Dayanna Guimarães. Docência no processo de inclusão do estudante com deficiência em cursos de Educação Física: análise do contexto universitário brasileiro e português. Tese (Doutorado em Educação) - Universidade Federal de Alagoas, Centro de Educação, Programa de Pós-Graduação em Educação, Maceió, 2016. Disponível em: http://www.repositorio.ufal.br/handle/riufal/1657. Acesso em: 21 dez. 2019.

SANTOS, João Henrique de Sousa; ROCHA, Bianca Ferreira; PASSAGLIO, Kátia Tomagnini. Extensão Universitária e Formação no Ensino Superior. Revista Brasileira de Extensão Universitária. Chapecó, v. 7, n. 1, maio 2016. Disponível em: https://periodicos.uffs.edu.br/index.php/RBEU/article/view/3087. Acesso em: 23 dez. 2019. 
A extensão em educação especial e o processo formativo de licenciandos

SILVEIRA, Denise Tolfo; CÓRDOVA, Fernanda Peixoto. A pesquisa científica. In: GERHARDT, Tatiana Engel; SILVEIRA, Denise Tolfo. (Orgs.). Métodos de pesquisa. Porto Alegre: Editora da UFRGS, 2009. p. 31-42.

SOUSA, Kelly Cristina de. A formação docente para a educação especial e a prática profissional do professor. Dissertação (Mestrado em Docência e Gestão da Educação) Faculdade de Ciências Humanas e Sociais, Universidade Fernando Pessoa, Porto, 2017. Disponível em: https://bdigital.ufp.pt/bitstream/10284/6041/4/DM_Kelly\%20de\%20Sousa.pdf. Acesso em: 22 dez. 2019.

TRAD, Leny Alves Bomfim. Grupos focais: conceitos, procedimentos e reflexões baseadas em experiências com o uso da técnica em pesquisas de saúde. Physis. Rio de Janeiro, v. 19, n. 3 , 2009. Disponível em: http://www.scielo.br/pdf/physis/v19n3/a13v19n3.pdf. Acesso em: 22 dez. 2019.

Recebido em: 29/09/2020

Aceito em: 16/08/2021 